Short Communication

\title{
Using Voltammetry and EIS for Analysis of Pottery Materials
}

\author{
Guangfu Liu ${ }^{1, *}$, Xinghua Yang ${ }^{1}$, Huaiwei Zhang ${ }^{2}$ and Li Fu ${ }^{1,2^{*}}$ \\ ${ }^{1}$ Henan Key Laboratory of Research for Central Plains Ancient Ceramics, Pingdingshan University, \\ Pingdingshan Henan, 467000 PR. China \\ ${ }^{2}$ College of Materials and Environmental Engineering, Hangzhou Dianzi University, Hangzhou \\ 310018, PR. China \\ "E-mail: $\underline{415 \operatorname{lgp} @ 163 . c o m ; ~ L i ~ F u ~ f u l i @ h d u . e d u . c n ; ~}$
}

doi: $10.20964 / 2020.06 .31$

Received: 2 February 2020 / Accepted: 29 March 2020 / Published: 10 May 2020

Due to the different materials and/or different production conditions used to make pottery, including temperature, roasting time and oxidation/reduction conditions, the voltammetric signal of pottery powder could be used for potential archaeological analysis. In this work, we selected black pottery, gray pottery and red pottery as examples to confirm the hypothesis. Differential pulse voltammetry and electrochemical impedance spectroscopy were used as analytical methods. The results indicate that the voltammetric signals of $\mathrm{Mn}$ and Fe species in the pottery samples could be used as evidence for pottery identification. The observed difference was also confirmed by XRF analysis and physical property analysis.

Keywords: Voltammetric signal; Pottery analysis; Electrochemistry; Electrochemical impedance spectroscopy; Solid-state electrochemistry

\section{FULL TEXT}

(C) 2020 The Authors. Published by ESG (www.electrochemsci.org). This article is an open access article distributed under the terms and conditions of the Creative Commons Attribution license (http://creativecommons.org/licenses/by/4.0/). 